\title{
Optimization of Hybrid Desalination Processes Including Multi Stage Flash and Reverse Osmosis Systems
}

\author{
Marian G. Marcovecchio ${ }^{1,2,3}$, Sergio F. Mussati1,4, \\ Nicolás J. Scenna ${ }^{1,4}$ and Pío A. Aguirre ${ }^{1,2}$ \\ ${ }^{1}$ INGAR/CONICET - Instituto de Desarrollo y Diseño, \\ Avellaneda 3657 S3002GJC, Santa Fe, \\ ${ }^{2} U N L$ - Universidad Nacional del Litoral, Santa Fe, \\ ${ }^{3}$ UMOSE/LNEG-Und. de Modelação e Optimização de Sist. Energéticos, Lisboa, \\ ${ }^{4}$ UTN/FRRo - Universidad Tecnológica Nacional, Rosario, \\ 1,2,4Argentina \\ ${ }^{3}$ Portugal
}

\section{Introduction}

Distillation and reverse osmosis are the two most common processes to obtain fresh water from seawater or brackish water.

A leading distillation method is the Multi Stage Flash process (MSF). For this method, fresh water is obtained by applying thermal energy to seawater feed in multiple stages creating a distillate stream for fresh water uses, and a concentrated (brine) stream that is returned to the sea.

In Reverse Osmosis processes (RO), the seawater feed is pumped at high pressure to special membranes, forcing fresh water to flow through the membranes. The concentrate (brine) remains on the upstream side of the membranes, and generally, this stream is passed through a mechanical energy recovery device before being discharged back to the sea.

Desalination plants require significant amounts of energy as heat or electricity form and significant amounts of equipments. Reverse osmosis plants typically require less energy than thermal distillation plants. However, the membrane replacement and the high-pressure pumps increase the $\mathrm{RO}$ production cost significantly. Furthermore, even the salt concentration of permeated stream is low; this stream is not free of salt, as the distillate stream produced by a MSF system.

Therefore, hybrid system combining thermal and membrane processes are being studied as promising options. Hybrid plants have potential advantages of a low power demand and improved water quality; meanwhile the recovery factor can be improved resulting in a lower operative cost as compared to stand alone RO or MSF plants.

Several models have already been described in the literature to find an efficient relationship between both desalination processes (Helal et al., 2003; Agashichev, 2004; Cardona \& Piacentino, 2004; Marcovecchio et al., 2005). However, these works analyse only specific fixed configurations for the RO-MSF hybridization. 
In this chapter, all the possible configurations for hybrid RO-MSF plants are analyzed in an integrated way. A super-structure model for the synthesis and optimization of these structures is presented. The objective is to determine the optimal plant designs and operating conditions in order to minimize the cost per $\mathrm{m}^{3}$ of fresh water satisfying a given demand. Specifically, the work (Marcovecchio et al., 2009) is properly extended, in order to study the effect of different seawater concentrations on the process configuration. This will allow finding optimal relationships between both processes at different conditions, for a given fresh water demand.

\section{Super-structure description}

The modelled superstructure addresses the problem of the synthesis and optimization of hybrid desalination plants, including the Multi Stage Flash process: MSF and the Reverse Osmosis process: RO. The total layout includes one MSF and two RO systems, in order to allow the possibility of choosing a process of reverse osmosis with two stages. Many of the existing RO plants adopt the two stages RO configurations, since in some cases it is the cheapest and most efficient option.

Figure 1 illustrates the modelled superstructure. All the possible alternative configurations and interconnections between the three systems are embedded. The seawater feed passes through a Sea Water Intake and Pre-treatment system (SWIP) where is chemically treated, according to MSF and RO requirements. As Figure 1 shows, the feed stream of each process is not restricted to seawater; instead, different streams can be blended to feed each system. Then, part of the rejected stream leaving a system may enter into another one, even itself, resulting in a recycle. The permeated streams of both RO systems and the distillate stream from MSF are blended to produce the product stream, whose salinity is restricted to not exceed a maximum allowed salt concentration. Furthermore, a maximum salt concentration is imposed for the blended stream which is discharged back to the sea, in order to prevent negative ecological effects.

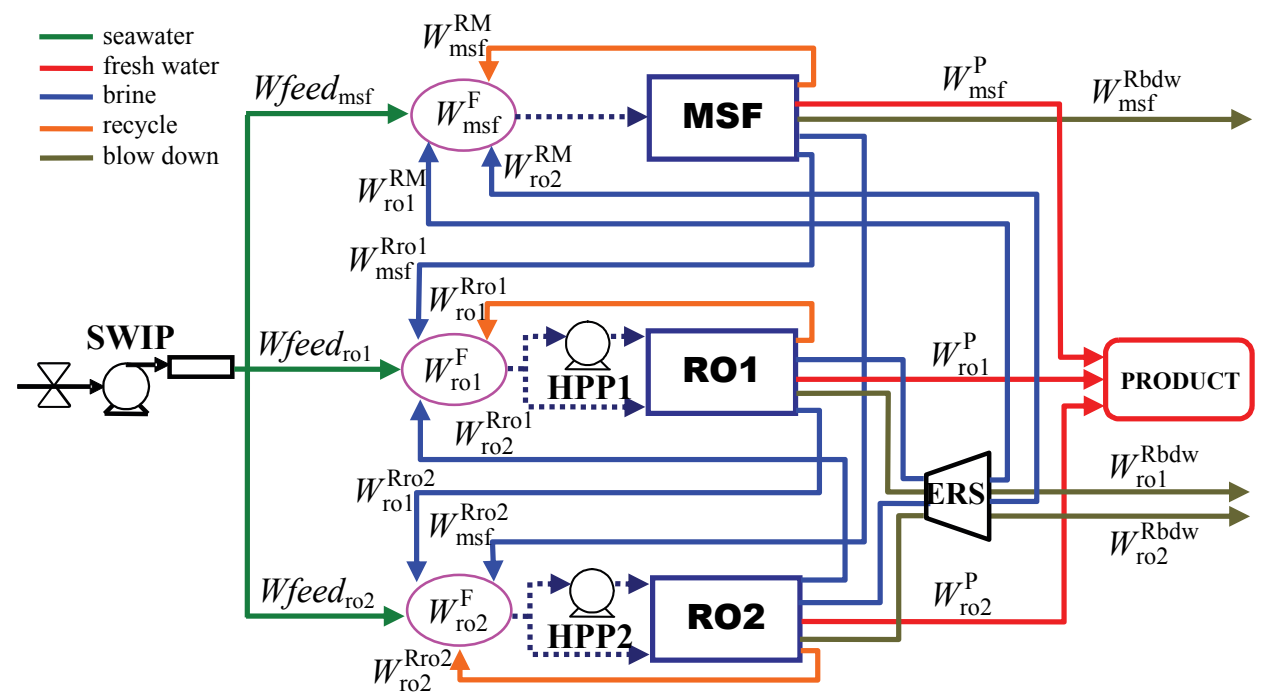

Fig. 1. Layout of the modelled superstructure 
Seawater characteristics: salt concentration and temperature are given data, as well as the demand to be satisfied: total production and its maximum allowed salt concentration. On the contrary, the flow rate of the seawater streams fed to each system are optimization variables, as well as the flow rate and salt concentration of the product, blow down and inner streams.

The operating pressures for each $\mathrm{RO}$ system are also optimization variables. If the pressure of the stream entering to a $\mathrm{RO}$ system is high enough, the corresponding high pressure pumps are eliminated. Moreover, the number of modules operating in parallel at each RO system is also determined by the optimization procedure. The remainder rejected flow rate of both RO systems, if they do exist, will pass through an energy recovery system, before being discharged back to the sea or fed into the MSF system.

For the MSF system, the geometrical design of the evaporator, the number of tubes in the pre-heater, the number of flash stages, and others are considered as optimization variables.

The complete mathematical model is composed by four major parts: The Multi Stage Flash model, The Reverse Osmosis model, network equations and cost equations. The following section focuses on each of these four parts of the model.

\section{Mathematical model}

\subsection{Multi Stage Flash model}

The model representing the MSF system is based on the work (Mussati et al., 2004). A brief description of the model is presented here.

The evaporator is divided into stages. Each stage has a seawater pheheater, a brine flashing chamber, a demister and a distillate collector. Figure 2 shows a flashing stage.

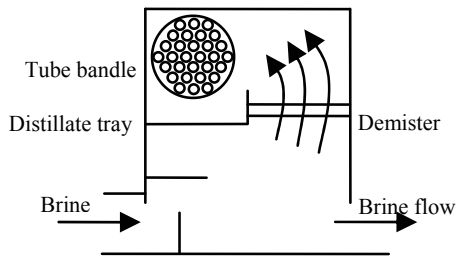

Fig. 2. Scheme of flashing stage

In a MSF system, feed stream passes through heating stages and is heated further in the heat recovery sections of each subsequent stage. Then, feed is heated even more using externally suplied steam. After that, the feedwater passes through various stages where flashing takes place. The vapor pressure at each stage is controlled in such way that the heated brine enters each chamber at the proper temperature and pressure to cause flahs operation. The flash vapor is drawn to the cooler tube bundle surfaces where it is condensed and collected as distillate and paseses on from stage to stage parallelly to the brine. The distillate stream is also flash-boiled, so it can be cooled and the surplus heat recovered for preheating the feed. Figure 3 shows an scheme of a MSF system with NS stages.

Often, part of the brine leaving the last stage is mixed with the incoming feedwater because it reduces the chemical pre-treatment cost. According to the interconections and recirculations considered in the modeled superstructure, two typical MSF operating modes are included: MSF-OT (without recycle) and MSF-BR (with recycle). However, more complex configurations are also included, since different streams can be blended (at different proportions) to feed the MSF system. 


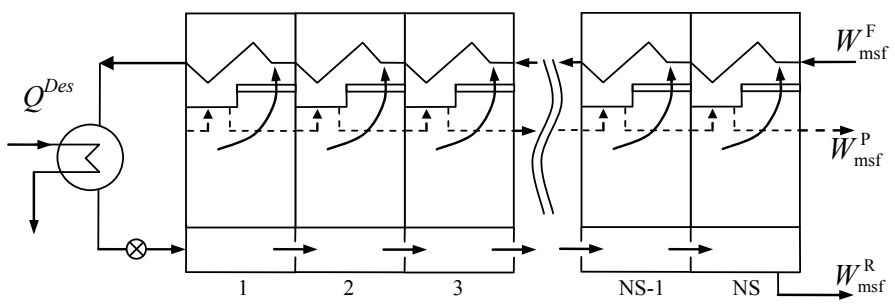

Fig. 3. MFS system

The MSF model considers all the most important aspects of the process.

The heat consumption is calculated by:

$$
\begin{gathered}
Q^{D e s}=W_{\mathrm{msf}}^{\mathrm{F}} C p_{\mathrm{msf}} \Delta t 10^{-6} \rho^{\mathrm{b}} \\
\Delta t=\Delta t_{f}+\Delta t_{e}+B P E
\end{gathered}
$$

Total heat transfer area and number of flash stages are calculated as:

$$
\begin{gathered}
A_{t}=\frac{W_{\mathrm{msf}}^{\mathrm{F}} 10^{3} C p_{\mathrm{msf}}}{U} \ln \left(\frac{\Delta t-B P E}{\Delta t_{e}}\right)^{\left(T_{\mathrm{max}}-\Delta t-T_{\mathrm{msf}}^{\mathrm{F}}\right) / \Delta t_{f}} \\
N S=\left(T_{\max }-\Delta t-T_{\mathrm{msf}}^{\mathrm{F}}\right) / \Delta t_{f}
\end{gathered}
$$

The total production of distillate is evaluated by:

$$
W_{\mathrm{msf}}^{\mathrm{P}}=W_{\mathrm{msf}}^{\mathrm{F}}\left[1-\left(1-\frac{C p_{\mathrm{msf}} \Delta t_{f}}{\lambda}\right)^{N S}\right]
$$

The following equation establishes a relation between heat transfer area, number of tubes and chamber width:

$$
A_{t}=\Pi T D B_{\mathrm{msf}} N_{t} N S
$$

The stage height can be approximated by:

$$
H s=2 L b+D s
$$

The number of rows of tubes in the vertical direction is related to the number of tubes in the following way:

$$
N_{r t}=0.481 T D \sqrt{N_{t}}
$$

The following equation relates the shell diameter to the number of rows of tubes and Pitch:

$$
D s=N_{r t} P_{t} \sqrt{2}
$$


The length of the desaltor is constrained by the following two equations:

$$
\begin{gathered}
L_{d}=\frac{W_{\mathrm{msf}}^{\mathrm{P}} 10^{-3}}{B_{\mathrm{msf}} V_{\text {vap }} \rho_{\text {vap }}} \\
L_{d}=\text { Ds NS }
\end{gathered}
$$

The total stage surface area is calculated by:

$$
A_{S}=2 L_{d} B_{\mathrm{msf}}+2 H s L_{d}+H s B_{\mathrm{msf}} N S
$$

Finally, the temperature of last flashing stage of the MSF system is calculated as:

$$
T_{\mathrm{msf}}^{\mathrm{R}}=T_{\max }-N S \Delta t_{f}=T_{\mathrm{msf}}^{\mathrm{F}}+\Delta t
$$

Despite the simplifying hypothesis assumed in the model, the MSF process is well represented and the solutions of this model are accurately enough to establish conclusions for the hybrid plant.

\subsection{Reverse osmosis model}

The model representing the RO system is based on the work (Marcovecchio et al., 2005). A brief description of the equations is presented here.

Each RO system is composed by permeators operating in parallel mode and under identical conditions. Particularly, data for DuPont B10 hollow fiber modules were adopted here. However, the model represents the permeation process for general hollow fiber modules and any other permeator could be considered providen the particular module parameters. Figure 4 represents the RO system modeled for the hybrid plant.

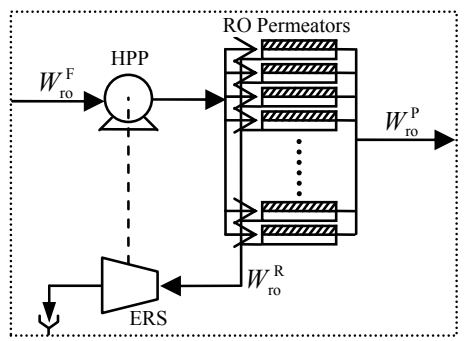

Fig. 4. RO system

Initially, pressure of inlet stream is raised by the High Pressure Pumps (HPP). Then, the pressurized stream passes through membrane modules, where permeation takes place. Part of the rejected stream could pass through the energy recovery system, before being discharged back to the sea or fed into the MSF system. Therefore, part of the power required for the whole plant is supplied by the energy recovery system, and the rest will be provided by an external source.

Equations (14) to (30) describe the permeation process taking place at one module of each system. 
The transport phenomena of solute and water through the membrane are modeled by the Kimura-Sourirajan model (Kimura \& Sourirajan, 1967):

$$
\begin{gathered}
J_{\mathrm{s}}^{\mathrm{w}}=3600 A\left(\bar{P}_{\mathrm{s}}^{\mathrm{b}}-\bar{P}_{\mathrm{s}}^{\mathrm{p}}-\frac{i R T_{\mathrm{s}} \rho^{\mathrm{b}}\left(C_{\mathrm{s}}^{\mathrm{m}}-C_{\mathrm{s}}^{\mathrm{P}}\right)}{10^{6} M s 101325}\right) \quad \mathrm{s}=\mathrm{ro} 1, \mathrm{ro} 2 \\
J_{\mathrm{s}}^{\mathrm{S}}=\frac{3600 B\left(C_{\mathrm{s}}^{\mathrm{m}}-C_{\mathrm{s}}^{\mathrm{P}}\right) \rho^{\mathrm{b}}}{10^{6}} \quad \mathrm{~s}=\mathrm{ro} 1, \mathrm{ro} 2
\end{gathered}
$$

The velocity of flow is:

$$
V_{\mathrm{s}}^{\mathrm{w}}=\frac{\left(J_{\mathrm{s}}^{\mathrm{w}}+J_{\mathrm{s}}^{\mathrm{S}}\right)}{\rho^{\mathrm{p}}} \quad \mathrm{s}=\mathrm{ro} 1, \mathrm{ro} 2
$$

The following equation gives the salt concentration of the permeate stream:

$$
C_{\mathrm{s}}^{\mathrm{P}}=\frac{J_{\mathrm{s}}^{\mathrm{S}} 10^{6}}{V_{\mathrm{s}}^{\mathrm{W}} \rho^{\mathrm{p}}} \quad \mathrm{s}=\mathrm{ro} 1, \mathrm{ro} 2
$$

Permeate flow rate is calculated as the product between the permeation velocity and the membrane area:

$$
Q_{\mathrm{s}}^{\mathrm{p}}=V_{\mathrm{s}}^{\mathrm{w}} A_{\mathrm{m}} \quad \mathrm{s}=\mathrm{ro} 1, \mathrm{ro} 2
$$

The total material balance for each permeator is:

$$
Q_{\mathrm{s}}^{\mathrm{f}}=Q_{\mathrm{s}}^{\mathrm{b}}+Q_{\mathrm{s}}^{\mathrm{p}} \quad \mathrm{s}=\mathrm{ro} 1, \mathrm{ro} 2
$$

The salt balance in each permeator is given by:

$$
Q_{\mathrm{s}}^{\mathrm{f}} C_{\mathrm{s}}^{\mathrm{F}}=Q_{\mathrm{s}}^{\mathrm{b}} C_{\mathrm{s}}^{\mathrm{R}}+Q_{\mathrm{s}}^{\mathrm{p}} C_{\mathrm{s}}^{\mathrm{P}} \quad \mathrm{s}=\mathrm{ro} 1, \mathrm{ro} 2
$$

The phenomenon of concentration polarization must be considered. The principal negative consequence of this phenomenon is a reduction in the fresh water flow. The approach widely used to model the influence of the concentration polarization is the film theory. The Sherwood, Reynolds and Schmidt numbers are combined in an empirical relation: equation (24) to calculate the mass transfer coefficient:

$$
\begin{gathered}
S h_{\mathrm{s}}=\frac{k_{\mathrm{s}} 2 r_{0}}{D} \quad \mathrm{~s}=\mathrm{ro} 1, \mathrm{ro} 2 \\
\operatorname{Re}_{\mathrm{s}}=\frac{2 r_{0} U_{\mathrm{s}}^{\mathrm{S}} \rho^{\mathrm{b}}}{\mu^{\mathrm{b}}} \quad \mathrm{s}=\mathrm{ro} 1, \mathrm{ro} 2 \\
S c_{\mathrm{s}}=\frac{\mu^{\mathrm{b}}}{\rho^{\mathrm{b}} D} \quad \mathrm{~s}=\mathrm{ro} 1, \mathrm{ro} 2
\end{gathered}
$$




$$
S h_{\mathrm{s}}=2.725\left(\operatorname{Re}_{\mathrm{s}}\right)^{1 / 3}\left(S c_{\mathrm{s}}\right)^{1 / 3} \quad \mathrm{~s}=\mathrm{ro} 1, \mathrm{ro} 2
$$

The concentration polarization phenomenon is modeled by:

$$
\frac{C_{\mathrm{s}}^{\mathrm{m}}-C_{\mathrm{s}}^{\mathrm{P}}}{C_{\mathrm{s}}^{\mathrm{R}}-C_{\mathrm{s}}^{\mathrm{P}}}=\exp \left(\frac{V_{\mathrm{s}}^{\mathrm{w}}}{3600 k_{\mathrm{s}}}\right) \quad \mathrm{s}=\mathrm{ro} 1, \mathrm{ro} 2
$$

In order to estimate the average pressure drop in the fiber bore and the average pressure drop on the shell side of the fiber bundle, it is necessary to calculate the superficial velocity in the radial direction. According to (Al-Bastaki \& Abbas, 1999), the superficial velocity can be approximated as the log mean average of the superficial velocity at the inner and outer radius of the fiber bundle:

$$
\begin{array}{ll}
U_{\mathrm{s}}^{\mathrm{si}}=\frac{Q_{\mathrm{s}}^{\mathrm{f}}}{36002 \Pi R_{\mathrm{i}} L} & \mathrm{~s}=\mathrm{ro} 1, \mathrm{ro} 2 \\
U_{\mathrm{s}}^{\mathrm{so}}=\frac{Q_{\mathrm{s}}^{\mathrm{f}}-V_{\mathrm{s}}^{\mathrm{w}} A_{\mathrm{m}}}{36002 \Pi R_{\mathrm{o}} L} & \mathrm{~s}=\mathrm{ro} 1, \mathrm{ro} 2 \\
U_{\mathrm{s}}^{\mathrm{s}}=\frac{U_{\mathrm{s}}^{\mathrm{si}}-U_{\mathrm{s}}^{\mathrm{so}}}{\log \left(U_{\mathrm{s}}^{\mathrm{si}} / U_{\mathrm{s}}^{\mathrm{so}}\right)} \quad \mathrm{s}=\mathrm{ro} 1, \mathrm{ro} 2
\end{array}
$$

The approximation for the pressure drop in the fiber bore is based on Hagen-Poiseuille's equation:

$$
\bar{P}_{\mathrm{s}}^{\mathrm{p}}=1+\frac{1}{2} \frac{16 \mu^{\mathrm{p}} r_{\mathrm{o}} V_{\mathrm{s}}^{\mathrm{w}} L^{2}}{3600 r_{\mathrm{i}}^{4} 101325} \quad \mathrm{~s}=\mathrm{ro} 1, \mathrm{ro} 2
$$

Similarly, the pressure drop on the shell side of the fiber bundle is estimated by Ergun's equation:

$$
\bar{P}_{\mathrm{s}}^{\mathrm{b}}=P_{\mathrm{s}}^{\mathrm{f}}-\frac{1}{2} \frac{150(1-\varepsilon)^{2} \mu^{\mathrm{b}} U_{\mathrm{s}}^{\mathrm{S}}}{\varepsilon^{3} d_{\mathrm{p}}^{2} 101325}\left(R_{\mathrm{o}}-R_{\mathrm{i}}\right)-\frac{1}{2} \frac{1.75(1-\varepsilon) \rho^{\mathrm{b}}\left(U_{\mathrm{s}}^{\mathrm{S}}\right)^{2}}{\varepsilon^{3} d_{\mathrm{p}} 101325}\left(R_{\mathrm{o}}-R_{\mathrm{i}}\right) \quad \text { s=ro1, ro2 }
$$

Finally, the total flow rates of feed and permeate for each system are given by:

$$
\begin{array}{ll}
W_{\mathrm{s}}^{\mathrm{F}}=N M_{\mathrm{s}} Q_{\mathrm{s}}^{\mathrm{f}} & \mathrm{s}=\mathrm{ro} 1, \mathrm{ro} 2 \\
W_{\mathrm{s}}^{\mathrm{P}}=N M_{\mathrm{s}} Q_{\mathrm{s}}^{\mathrm{p}} & \mathrm{s}=\mathrm{ro} 1, \mathrm{ro} 2
\end{array}
$$

The chosen model considers all the most important aspects affecting the permeation process. Even thought, differential equations involved in the modeling are estimated without any discretization, the whole model is able to predict the flow of fresh water and salt trough the membrane in an accuracy way. 


\subsection{Network equations}

The overall superstructure is modelled in such way that all the interconnections between the three systems are allowed, as it shown in Figure 1.

In effect, part of the rejected stream of each system can enter into another system, even itself. The fractions of rejected streams of RO systems that will enter into MSF system or that will be discharged back to the sea, will pass through the ERS. On the contrary, the fractions of rejected streams of RO systems that will enter into a RO system again, will not pass through the ERS, because the plant could benefit from these high pressurized streams. In fact, when all the streams entering to a RO system flow at a high enough pressure, the corresponding HPPs can be avoided. That RO system would correspond to a second stage of reverse osmosis. In that case, the pressure of all the inlet streams will be levelled to the lowest one, by using appropriated valves. However, if at least one of the RO inlet streams is coming from MSF system or from sea, the pressure of all the inlet streams will be lowered to atmospheric pressure, and before entering membrane modules, HPPs will be required. The network and cost equations are formulated is such way that the optimization procedure can decide the existence or not of HPPs and this decision is correctly reflected in the cost functions. When the whole model is optimized, the absence of a particular stream is indicated by the corresponding flow rate being zero. Furthermore, the optimization procedure could decide the complete elimination of one system for the optimal design. The energy and material balances guarantee the correct definition of each stream.

The total fresh water demand is $2000 \mathrm{~m}^{3} / \mathrm{h}$ and is the result of blending the product stream of each system:

$$
W_{\mathrm{msf}}^{\mathrm{P}}+W_{\mathrm{ro1}}^{\mathrm{P}}+W_{\mathrm{ro} 2}^{\mathrm{P}}=\operatorname{prodc}
$$

The fresh water stream must not exceed a maximum allowed salt concentration. This requirement is imposed by the following constraint, taking into account that distillate stream is free of salt, but permeate RO streams are not.

$$
c_{\max } \geq\left(N M_{\mathrm{ro} 1} Q_{\mathrm{ro} 1}^{\mathrm{p}} C_{\mathrm{ro} 1}^{\mathrm{P}}+N M_{\mathrm{ro} 2} Q_{\mathrm{ro} 2}^{\mathrm{p}} C_{\mathrm{ro} 2}^{\mathrm{P}}\right) / \text { prodc }
$$

For ecological reasons, the salinity of the blended stream which is discharged back to the sea must not be excessively high. An acceptable maximum value for this salinity is $67000 \mathrm{ppm}$ :

$$
C_{\mathrm{msf}}^{\mathrm{R}} W_{\mathrm{msf}}^{\mathrm{Rbdw}}+C_{\mathrm{ro} 1}^{\mathrm{R}} W_{\mathrm{ro} 1}^{\mathrm{Rbdw}}+C_{\mathrm{ro} 2}^{\mathrm{R}} W_{\mathrm{ro} 2}^{\mathrm{Rbdw}} \leq 67000\left(W_{\mathrm{msf}}^{\mathrm{Rbdw}}+W_{\mathrm{ro} 1}^{\mathrm{Rbdw}}+W_{\mathrm{ro} 2}^{\mathrm{Rbdw}}\right)
$$

By considering all the possible streams that can feed MSF system, the following equations give the flow rate of MSF feed stream:

$$
W_{\mathrm{msf}}^{\mathrm{F}}=W \text { feed }_{\mathrm{msf}}+W_{\mathrm{msf}}^{\mathrm{RM}}+W_{\mathrm{ro} 1}^{\mathrm{RM}}+W_{\mathrm{ro} 2}^{\mathrm{RM}}
$$

Consequently, salt and energy balances for MSF feed are:

$$
\begin{gathered}
C_{\mathrm{msf}}^{\mathrm{F}} W_{\mathrm{msf}}^{\mathrm{F}}=C \text { feed } W \text { feed } \mathrm{msf}+C_{\mathrm{msf}}^{\mathrm{R}} W_{\mathrm{msf}}^{\mathrm{RM}}+C_{\mathrm{ro} 1}^{\mathrm{R}} W_{\mathrm{ro} 1}^{\mathrm{RM}}+C_{\mathrm{ro} 2}^{\mathrm{R}} W_{\mathrm{ro} 2}^{\mathrm{RM}} \\
T_{\mathrm{msf}}^{\mathrm{F}} W_{\mathrm{msf}}^{\mathrm{F}}=T \text { feed } W \text { ffeed }_{\mathrm{msf}}+T_{\mathrm{msf}}^{\mathrm{R}} W_{\mathrm{msf}}^{\mathrm{RM}}+T_{\mathrm{ro} 1} W_{\mathrm{ro} 1}^{\mathrm{RM}}+T_{\mathrm{ro} 2} W_{\mathrm{ro} 2}^{\mathrm{RM}}
\end{gathered}
$$


The overall mass and salt balances for MSF system are given by:

$$
\begin{gathered}
W_{\mathrm{msf}}^{\mathrm{F}}=W_{\mathrm{msf}}^{\mathrm{P}}+W_{\mathrm{msf}}^{\mathrm{RM}}+W_{\mathrm{msf}}^{\mathrm{Rro} 1}+W_{\mathrm{msf}}^{\mathrm{Rro2}}+W_{\mathrm{msf}}^{\mathrm{Rbdw}} \\
C_{\mathrm{msf}}^{\mathrm{F}} W_{\mathrm{msf}}^{\mathrm{F}}=C_{\mathrm{msf}}^{\mathrm{R}}\left(W_{\mathrm{msf}}^{\mathrm{RM}}+W_{\mathrm{msf}}^{\mathrm{Rro1}}+W_{\mathrm{msf}}^{\mathrm{Rro} 2}+W_{\mathrm{msf}}^{\mathrm{Rbdw}}\right)
\end{gathered}
$$

Similarly to equation (36), the following equations give the flow rate of RO feed streams:

$$
\begin{aligned}
& W_{\mathrm{ro} 1}^{\mathrm{F}}=W \text { ffeed }_{\mathrm{ro1}}+W_{\mathrm{msf}}^{\mathrm{Rro1}}+W_{\mathrm{ro1}}^{\mathrm{Rro1}}+W_{\mathrm{ro} 2}^{\mathrm{Rro} 1} \\
& W_{\mathrm{ro} 2}^{\mathrm{F}}=W_{\text {feed }}{ }_{\mathrm{ro} 2}+W_{\mathrm{msf}}^{\mathrm{Rro2}}+W_{\mathrm{ro1}}^{\mathrm{Rro2}}+W_{\mathrm{ro2}}^{\mathrm{Rro} 2}
\end{aligned}
$$

Equations (43) and (44) establish the division of the total rejected stream leaving each RO system in the different assignations:

$$
\begin{aligned}
& N M_{\mathrm{ro} 1} Q_{\mathrm{ro} 1}^{\mathrm{b}}=W_{\mathrm{ro} 1}^{\mathrm{RM}}+W_{\mathrm{ro} 1}^{\mathrm{Rro1}}+W_{\mathrm{ro} 1}^{\mathrm{Rro} 2}+W_{\mathrm{ro} 1}^{\mathrm{Rbdw}} \\
& N M_{\mathrm{ro} 2} Q_{\mathrm{ro} 2}^{\mathrm{b}}=W_{\mathrm{ro} 2}^{\mathrm{RM}}+W_{\mathrm{ro} 2}^{\mathrm{Rro} 1}+W_{\mathrm{ro} 2}^{\mathrm{Rro} 2}+W_{\mathrm{ro} 2}^{\mathrm{Rbdw}}
\end{aligned}
$$

The salt balances for RO system feeds are:

$$
\begin{aligned}
& C_{\mathrm{ro} 1}^{\mathrm{F}} W_{\mathrm{ro} 1}^{\mathrm{F}}=\text { Cffeed }_{W} \text { ffeed }_{\mathrm{ro1}}+C_{\mathrm{msf}}^{\mathrm{R}} W_{\mathrm{msf}}^{\mathrm{Rro1}}+C_{\mathrm{ro} 1}^{\mathrm{R}} W_{\mathrm{ro} 1}^{\mathrm{Rro1}}+C_{\mathrm{ro} 2}^{\mathrm{R}} W_{\mathrm{ro} 2}^{\mathrm{Rro} 1} \\
& C_{\mathrm{ro} 2}^{\mathrm{F}} W_{\mathrm{ro} 2}^{\mathrm{F}}=C \text { feed } W \text { ffeed }_{\mathrm{ro} 2}+C_{\mathrm{msf}}^{\mathrm{R}} W_{\mathrm{msf}}^{\mathrm{Rro} 2}+C_{\mathrm{ro} 1}^{\mathrm{R}} W_{\mathrm{ro} 1}^{\mathrm{Rro} 2}+C_{\mathrm{ro} 2}^{\mathrm{R}} W_{\mathrm{ro} 2}^{\mathrm{Rro} 2}
\end{aligned}
$$

Meanwhile, energy balances for RO systems feeds are given by:

$$
\begin{aligned}
& T_{\text {ro1 }} W_{\text {ro1 }}^{\mathrm{F}}=\text { Tfeed } W \text { feed }_{\mathrm{ro} 1}+T_{\mathrm{msf}}^{\mathrm{R}} W_{\mathrm{msf}}^{\mathrm{Rro1}}+T_{\mathrm{ro} 1} W_{\mathrm{ro} 1}^{\mathrm{Rro} 1}+T_{\mathrm{ro} 2} W_{\mathrm{ro} 2}^{\mathrm{Rro1}} \\
& T_{\mathrm{ro} 2} W_{\mathrm{ro} 2}^{\mathrm{F}}=\text { Tfeed } W_{\text {feed }}{ }_{\mathrm{ro} 2}+T_{\mathrm{msf}}^{\mathrm{R}} W_{\mathrm{msf}}^{\mathrm{Rro} 2}+T_{\mathrm{ro1}} W_{\mathrm{ro} 1}^{\mathrm{Rro} 2}+T_{\mathrm{ro} 2} W_{\mathrm{ro} 2}^{\mathrm{Rro} 2}
\end{aligned}
$$

The overall mass balances for RO systems are:

$$
\begin{aligned}
& W_{\mathrm{ro} 1}^{\mathrm{F}}=W_{\mathrm{ro} 1}^{\mathrm{P}}+W_{\mathrm{ro1}}^{\mathrm{RM}}+W_{\mathrm{ro1}}^{\mathrm{Rro1}}+W_{\mathrm{ro} 1}^{\mathrm{Rro2}}+W_{\mathrm{ro1}}^{\mathrm{Rbdw}} \\
& W_{\mathrm{ro} 2}^{\mathrm{F}}=W_{\mathrm{ro} 2}^{\mathrm{P}}+W_{\mathrm{ro} 2}^{\mathrm{RM}}+W_{\mathrm{ro} 2}^{\mathrm{Rro} 1}+W_{\mathrm{ro} 2}^{\mathrm{Rro2}}+W_{\mathrm{ro} 2}^{\mathrm{Rbdw}}
\end{aligned}
$$

The following equations establish the overall salt balances for RO systems:

$$
\begin{aligned}
& C_{\mathrm{ro} 1}^{\mathrm{F}} W_{\mathrm{ro} 1}^{\mathrm{F}}=C_{\mathrm{ro} 1}^{\mathrm{P}} W_{\mathrm{ro} 1}^{\mathrm{P}}+C_{\mathrm{ro} 1}^{\mathrm{R}}\left(W_{\mathrm{ro} 1}^{\mathrm{RM}}+W_{\mathrm{ro} 1}^{\mathrm{Rro1}}+W_{\mathrm{ro} 1}^{\mathrm{Rro} 2}+W_{\mathrm{ro} 1}^{\mathrm{Rbdw}}\right) \\
& C_{\mathrm{ro} 2}^{\mathrm{F}} W_{\mathrm{ro} 2}^{\mathrm{F}}=C_{\mathrm{ro} 2}^{\mathrm{P}} W_{\mathrm{ro} 2}^{\mathrm{P}}+C_{\mathrm{ro} 2}^{\mathrm{R}}\left(W_{\mathrm{ro} 2}^{\mathrm{RM}}+W_{\mathrm{ro} 2}^{\mathrm{Rro} 1}+W_{\mathrm{ro} 2}^{\mathrm{Rro} 2}+W_{\mathrm{ro} 2}^{\mathrm{Rbdw}}\right)
\end{aligned}
$$

Equations (53) to (60) assign to the variables $P_{\text {ro } 1}{ }^{\text {in }}$ and $P_{\text {ro } 2}{ }^{\text {in }}$ the minimal pressure over all the flows entering to the corresponding $\mathrm{RO}$ system. This assignation will allow the model to decide whether the HPPs before each RO system are necessary or not. In fact, if the minimal 
pressure of the inlet streams: $P$ in is equal or greater than the pressure needed to pass through the membrane modules: $P$ f then the corresponding HPPs are not necessary. On the other hand, if the value of $P$ in does not reach the operating pressure $P^{\mathrm{f}}$, then the corresponding HPPs cannot be avoided. In the following section, this decision will be modelled by the cost functions.

If the stream feeding the RO1 system includes part of brine stream leaving the MSF system, equation (53) imposes that the corresponding variable $P_{\mathrm{ro}}{ }^{\text {in }}$ be lower or equal than atmospheric pressure. On the contrary, if no stream coming from MSF system is feeding the RO1 system (i.e. $W_{\mathrm{msf}}{ }^{R r o 1}=0$ ), then constraint (53) does not affect variable $P_{\text {ro1 }}$ in at all. Equation (56) performs the same imposition by evaluating the existence or not of stream coming from the sea in the RO1 feed.

Equations (54) and (55) evaluate the existence of streams coming from an RO system and feeding RO1 system. If any of these streams does exist (i.e. $W_{\text {ro1 }} R_{\text {ro1 }}>0$ or $W_{\text {ro2 }}{ }^{\text {Rro1 }}>0$ ), the variable $P_{\text {ro } 1}{ }^{\text {in }}$ is imposed to be lower than the pressure of the corresponding stream.

$$
\begin{aligned}
& W_{\mathrm{msf}}^{\mathrm{Rro1}}\left(P_{\mathrm{ro} 1}^{\mathrm{in}}-1\right) \leq 0 \\
& W_{\text {ro1 }}^{\text {Rro1 }}\left(P_{\text {ro1 }}^{\text {in }}-\left(2 P_{\text {ro1 }}^{\mathrm{b}}-P_{\text {ro1 }}^{\mathrm{f}}\right)\right) \leq 0 \\
& W_{\text {ro2 }}^{\mathrm{Rro}}\left(P_{\mathrm{ro} 1}^{\mathrm{in}}-\left(2 P_{\text {ro2 }}^{\mathrm{b}}-P_{\text {ro2 }}^{\mathrm{f}}\right)\right) \leq 0 \\
& \text { Wfeed }_{\text {ro1 }}\left(P_{\text {ro1 }}^{\text {in }}-1\right) \leq 0
\end{aligned}
$$

Equations (57) to (60) act in analogous way to the four previous ones for the system RO2.

$$
\begin{aligned}
& W_{\mathrm{msf}}^{\mathrm{Rro} 2}\left(P_{\mathrm{ro} 2}^{\mathrm{in}}-1\right) \leq 0 \\
& W_{\text {ro1 }}^{\text {Rro2 }}\left(P_{\text {ro2 }}^{\text {in }}-\left(2 P_{\text {ro1 }}^{\mathrm{b}}-P_{\text {ro1 }}^{\mathrm{f}}\right)\right) \leq 0 \\
& W_{\text {ro2 }}^{\mathrm{Rro}}\left(P_{\mathrm{ro} 2}^{\mathrm{in}}-\left(2 P_{\mathrm{ro} 2}^{\mathrm{b}}-P_{\text {ro2 }}^{\mathrm{f}}\right)\right) \leq 0 \\
& W_{\text {feed }}\left(P_{\text {ro2 }}^{\text {in }}-1\right) \leq 0
\end{aligned}
$$

When the HPPs before an RO system are avoided, it is not convenient that the corresponding system operates at pressure lower than the available one. The following equations guarantee that, and also ensure the correct definition of associated cost functions.

$$
\begin{aligned}
& P_{\text {ro1 }}^{\mathrm{f}} \geq P_{\text {ro1 }}^{\mathrm{in}} \\
& P_{\text {ro2 }}^{\mathrm{f}} \geq P_{\text {ro2 }}^{\mathrm{in}}
\end{aligned}
$$

Most of the constraints presented in this section are complementary to the cost functions described in the following section. 


\subsection{Cost equations}

This section describes the cost equations of the total plant. The objective function to be minimized is the cost per $\mathrm{m}^{3}$ of produced fresh water. Capital and operating costs are calculated. The cost equations were formulated in such way that they can correctly reflect the presence or absence of equipments, streams or systems.

Capital costs are calculated by equations (63) to (67), while equations (69) to (76) estimate the operating ones.

Cost function reported by (Malek et al., 1996) was adopted in order to estimate capital cost for the SWIP:

$$
c c_{\text {swip }}=996\left(\left(\text { Wfeed }_{\mathrm{msf}}+\text { Wfeed }_{\mathrm{ro} 1}+\text { Wfeed }_{\mathrm{ro2}}\right) 24\right)^{0.8}
$$

Capital cost of HPP is defined in the same way. As it was explained at section 3.3, the variables $P$ in assume the minimal pressure over all the streams feeding a RO system, while $P^{f}$ is the operating pressure of the system. Equations (64) and (65) along with the optimization procedure, will make the variables $c_{\text {hpp }}$ to assume the capital cost of the HPP only when $P \mathrm{f}>P$ in, otherwise $c c_{\text {hpp }}$ will assume value null.

$$
\begin{aligned}
& \left(c c_{\mathrm{hpp} 1}-\frac{W_{\mathrm{ro} 1}^{\mathrm{F}}}{450}\left(393000+10710 P_{\mathrm{ro} 1}^{\mathrm{f}} 1.01325\right)\right) \cdot\left(P_{\mathrm{ro} 1}^{\mathrm{f}}-P_{\text {ro1 }}^{\mathrm{in}}\right) \geq 0 \\
& \left(c c_{\mathrm{hpp} 2}-\frac{W_{\mathrm{ro} 2}^{\mathrm{F}}}{450}\left(393000+10710 P_{\mathrm{ro} 2}^{\mathrm{f}} 1.01325\right)\right) \cdot\left(P_{\mathrm{ro} 2}^{\mathrm{f}}-P_{\mathrm{ro} 2}^{\mathrm{in}}\right) \geq 0
\end{aligned}
$$

Capital cost of the ERS is similar to the HPP one, since it consists of a reverse running centrifugal pump. Taking into account flow rate and pressure of the streams passing through the ERS, the capital cost is given by:

$$
\begin{aligned}
\mathcal{C C}_{\mathrm{ers}}= & \frac{\left(W_{\mathrm{ro} 1}^{\mathrm{Rbdw}}+W_{\mathrm{ro} 1}^{\mathrm{RM}}\right)}{450}\left(393000+10710\left(2 P_{\mathrm{ro} 1}^{\mathrm{b}}-P_{\mathrm{ro} 1}^{\mathrm{f}}\right) 1.01325\right)+ \\
& \frac{\left(W_{\mathrm{ro} 2}^{\mathrm{Rbdw}}+W_{\mathrm{ro} 2}^{\mathrm{RM}}\right)}{450}\left(393000+10710\left(2 P_{\mathrm{ro} 2}^{\mathrm{b}}-P_{\mathrm{ro} 2}^{\mathrm{f}}\right) 1.01325\right)
\end{aligned}
$$

The capital cost considered for the MSF system is the one due to the heat transfer area. According to (Mussati et al., 2006) this cost can be estimated as:

$$
\mathcal{C C}_{\text {area }}=\left(A_{t}+A_{S} 25\right) 50
$$

Therefore, the plant equipment cost is: $\mathcal{C C}_{\mathrm{eq}}=\mathcal{c C}_{\text {swip }}+\mathcal{C C}_{\mathrm{hpp} 1}+\mathcal{C C}_{\mathrm{hpp} 2}+\mathcal{c C}_{\text {area }}$. Civil work cost is estimated as a $10 \%$ of $c C_{\text {eq }}$ (Wade, 2001). Indirect cost is estimated in the same way (Helal et al., 2003). Then, the Total Capital Cost (TCC) is given by:

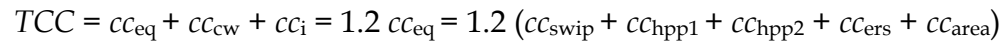

Capital charge cost is estimated as a $8 \%$ of the total capital cost (Malek et al., 1996):

$$
\mathrm{Co}_{\mathrm{c}}=0.08 \mathrm{TCC}
$$


The cost due to permeators is included as operative cost, by calculating their annualized installation cost and considering the replacement of $20 \%$ of permeators per year. According to (Wade, 2001) this sum can be estimated as $\$ 397.65$ per module per year.

$$
c O_{\mathrm{rp}}=\left(N M_{\mathrm{ro} 1}+N M_{\mathrm{ro} 2}\right) 397.65
$$

Energy cost is calculated by using the cost function given in (Malek et al., 1996) and the power cost reported in (Wade, 2001). The energy required by the SWIP and the HPP; and the energy provided by the ERS must be taken into account:

$$
\begin{gathered}
c 0_{\mathrm{e}}=0.03 f_{\mathrm{c}}\left(\frac{P_{\text {swip }}\left(W f e e d_{\mathrm{msf}}+W_{\text {ffeed }} \mathrm{ro1}\right.}{e f f_{\mathrm{swip}}}\right. \\
+\frac{\left.\left(P_{\mathrm{ro} 1}^{\mathrm{f}}-P_{\mathrm{ro} 1}^{\mathrm{in}}\right) 1.01325 W_{\mathrm{ro} 2}\right) 24}{e f f_{\mathrm{hpp}}}+\frac{\left(P_{\mathrm{ro} 2}^{\mathrm{f}}-P_{\mathrm{ro} 2}^{\mathrm{in}}\right) 1.01325 W_{\mathrm{ro} 2}^{\mathrm{F}} 24}{e f f_{\mathrm{hpp}}} \\
-e f f_{\mathrm{ers}} 1.01325\left(2 P_{\mathrm{ro} 1}^{\mathrm{b}}-P_{\mathrm{ro} 1}^{\mathrm{f}}\right) 24\left(W_{\mathrm{ro} 1}^{\mathrm{Rbdw}}+W_{\mathrm{ro} 1}^{\mathrm{RM}}\right)-e f f_{\mathrm{ers}} 1.01325\left(2 P_{\mathrm{ro} 2}^{\mathrm{b}}-P_{\mathrm{ro} 2}^{\mathrm{f}}\right) 24\left(W_{\mathrm{ro} 2}^{\mathrm{Rbdw}}+W_{\mathrm{ro} 2}^{\mathrm{RM}}\right)
\end{gathered}
$$

Spares costs are calculated by using the estimated values reported by (Wade, 2001):

$$
c o_{\mathrm{s}}=24365\left(W_{\mathrm{ro} 1}^{\mathrm{P}}+W_{\mathrm{ro} 2}^{\mathrm{P}}\right) f_{\mathrm{c}} 0.033+24365 W_{\mathrm{msf}}^{\mathrm{P}} f_{\mathrm{c}} 0.082
$$

Chemical treatment costs is calculated using the cost per $\mathrm{m}^{3}$ of feed reported in (Helal et al., 2003):

$$
\begin{gathered}
c_{\mathrm{ch}}=24365\left(\text { Wfeed }_{\mathrm{ro} 1}+W_{\mathrm{msf}}^{\mathrm{Rro} 1}+W_{\text {feed }} \mathrm{ro2}+W_{\mathrm{msf}}^{\mathrm{Rro} 2}\right) f_{\mathrm{c}} 0.018 \\
+24365\left(\text { Wfeed }_{\mathrm{msf}}+W_{\mathrm{ro} 1}^{\mathrm{RM}}+W_{\mathrm{ro} 2}^{\mathrm{RM}}\right) f_{\mathrm{c}} 0.024
\end{gathered}
$$

General operation and maintenance cost is calculated according to the value per $\mathrm{m}^{3}$ of produced water reported in (Wade, 2001):

$$
c o_{\mathrm{om}}=24365\left(W_{\mathrm{msf}}^{\mathrm{P}}+W_{\mathrm{ro} 1}^{\mathrm{P}}+W_{\mathrm{ro} 2}^{\mathrm{P}}\right) f_{\mathrm{c}} 0.126
$$

Similarly, power cost for MSF system is evaluated according to (Wade, 2001):

$$
c o_{\mathrm{pw}}=24365 W_{\mathrm{msf}}^{\mathrm{P}} f_{\mathrm{c}} 0.109
$$

The cost of the heat consumed by MSF system is calculated by using the function proposed by (Helal et al., 2003):

$$
c o_{\mathrm{ht}}=24365 f_{\mathrm{c}}\left(Q^{\text {Des }} 10^{6} / \lambda\right)\left(T_{\max }-323\right) 0.00415 / 85
$$

Finally, the Annual Operating Cost (AOC) is given by:

$$
A O C=\mathrm{CO}_{\mathrm{c}}+\mathrm{CO}_{\mathrm{rp}}+\mathrm{CO}_{\mathrm{e}}+\mathrm{CO}_{\mathrm{s}}+\mathrm{CO}_{\mathrm{ch}}+\mathrm{CO}_{\mathrm{om}}+\mathrm{CO}_{\mathrm{pw}}+\mathrm{CO}_{\mathrm{ht}}
$$

By considering a plant life of 25 years $(n)$ and a discount rate of $8 \%(i)$, capital recovery factor can be calculated, giving: $\operatorname{crf}=\left((i+1)^{n}-1\right) /\left(i(i+1)^{n}\right)$. Finally, fresh water cost per $\mathrm{m}^{3}$ is given by: 


$$
\cos t=\frac{T C C / c r f+A O C}{\text { prodc } 24365}
$$

Equations (1) to (78) define the model for the design and operation of a hybrid desalination plant, including MSF and RO systems.

In the following section, this model will be optimized for different seawater salt concentrations, and the obtained solutions will be analysed.

\section{Results: Optimal plant designs and operating conditions}

In this section optimized results are presented and discussed.

The proposed optimization problem $\mathrm{P}$ is defined as follows:

$$
\text { P: } \quad \text { minimize cost }
$$

$$
\text { s. t. } \quad \text { Equations (1) to (78) }
$$

while all the variables have appropriated bounds.

The optimization procedure will look for the optimal layout and operating conditions in order to minimize the cost per $\mathrm{m}^{3}$ of produced fresh water.

It is important to note that almost all discrete decisions were modelled exploiting the actual value of flow rates and pressures. Thus, no binary decision variables were included into the model. Only four integer variables are involved: the number of flash stages and the number of tubes in the pre-heater at the MSF system; and the number of permeators operating in

\begin{tabular}{|c|c|}
\hline \multicolumn{2}{|l|}{ Parameters for RO systems } \\
\hline$i$, number of ions for ionized solutes & 2 \\
\hline$R$, ideal gas constant, $\mathrm{N} \mathrm{m}$ / kgmole $\mathrm{K}$ & 8315 \\
\hline Ms, solute molecular weight & 58.8 \\
\hline $\mathrm{T}$, seawater temperature, ${ }^{\circ} \mathrm{C}$ & 25 \\
\hline$\rho^{\mathrm{b}}$, brine density, $\mathrm{kg} / \mathrm{m}^{3}$ & 1060 \\
\hline$\rho^{p}$, pure water density, $\mathrm{kg} / \mathrm{m}^{3}$ & 1000 \\
\hline$\mu_{\mathrm{P}}^{\mathrm{P}}$, permeated stream viscosity, $\mathrm{kg} / \mathrm{m} \mathrm{s}$ & $0.9 \times 10^{-3}$ \\
\hline$\mu^{\mathrm{b}}$, brine viscosity, $\mathrm{kg} / \mathrm{m} \mathrm{s}$ & $1.09 \times 10^{-3}$ \\
\hline$D$, diffusivity coefficient, $\mathrm{m}^{2} / \mathrm{s}$ & $1 \times 10^{-9}$ \\
\hline$P_{\text {swip, }}$ SWIP outled pressure, bar & 5 \\
\hline eff $f_{\text {swip, }}$ intake pump efficiency & 0.74 \\
\hline 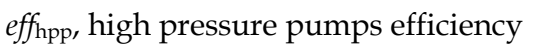 & 0.74 \\
\hline effers, energy recovery system efficiency & 0.80 \\
\hline$f_{c}$, load factor & 0.90 \\
\hline
\end{tabular}
parallel at each RO system.

Tables 1 and 2 list the parameter values used for the RO and MSF systems, respectively.

Table 1. Parameters for RO systems 
Parameters and operating ranges of the particular hollow fiber permeator were taken from (Al-Bastaki \&Abbas, 1999; Voros et al., 1997). These specifications constitute constants and bounds for some variables of the model.

\begin{tabular}{lc}
\hline \multicolumn{2}{c}{ Parameters for MSF system } \\
\hline$T_{\max }, \mathrm{K}$ & 385 \\
$C p_{\mathrm{msf}}, \mathrm{Kcal} /(\mathrm{kg} \mathrm{K})$ & 1 \\
$\mathrm{TD}, \mathrm{m}$ & 0.030 \\
Pitch: $P_{t}$ & 1.15 \\
$B P E, \mathrm{~K}$ & 1.9 \\
$U, \mathrm{Kcal} / \mathrm{m}^{2} / \mathrm{K} / \mathrm{h}$ & 2000 \\
$\lambda, \mathrm{Kcal} / \mathrm{Kg}$ & 550 \\
\hline
\end{tabular}

Table 2. Parameters for MSF system

The optimization model was implemented in General Algebraic Modeling System: GAMS (Brooke et al., 1997) at a Pentium 4 of $3.00 \mathrm{GHz}$. At first, the MINLP solver DICOPT was implemented to solve the problem. Unfortunately, the solver failed to find even a feasible solution for most case studies. Then, other resolution strategy was carried out in order to tackle the problem and obtain the optimal solutions.

Since it involves only 4 integer variables, the problem was solved in 2 steps. Firstly, the relaxed NLP problem was solved, i.e., the integer variables were relaxed to continuous ones. Departing from the optimal solution of the relaxed problem, the MINLP was solved by fixing the integer variables at the nearest integer values and optimizing the remaining variables. Since the MINLP problem presents a lot of non-convexities, a global search strategy was also implemented. In fact, for each study case, the previous 2 steps were repeated starting the optimization search from different initial points, and then, the best local optimal solution was selected. The generalized reduced gradient algorithm CONOPT was used as NLP solver. This resolution procedure was successful, providing optimal solutions in all case studies. The total CPU time required to solve all the cases was $1.87 \mathrm{~s}$, what proves that the proposed procedure is highly efficient and the model is mathematically good conditioned.

11 case studies were solved for seawater salt concentration going from 35000 ppm up to $45000 \mathrm{ppm}$. The total production was fixed at $2000 \mathrm{~m}^{3} / \mathrm{h}$ with a maximum allowed salt concentration of $570 \mathrm{ppm}$.

Table 3 shows the values of the main interconnection variables for the optimal solutions: feed flow rates, product and internal streams, as well as their salt concentrations.

Table 4 reports design variables and operating conditions for each process for the optimal solutions.

For seawater salt concentrations between 35000 and 38000 ppm, the optimal solutions do not include the MSF system. In fact, for these salinities, the optimal hybrid plant designs consist on a typical two stage RO plant. However, if the seawater salinity is greater than $38000 \mathrm{ppm}$, both desalination processes are present in the optimal design of the plant; that is: including MSF system is profitable.

Figure 5 shows a scheme of the optimal design of the plant obtained for seawater salinities between 35000 and 38000 ppm. 


\begin{tabular}{|c|c|c|c|c|c|c|c|c|}
\hline \multicolumn{9}{|c|}{ Optimal solutions for the hybrid plant: MSF-RO. Total Production: $2000 \mathrm{~m}^{3} / \mathrm{h}$. Maximum allowed salt concentration } \\
\hline Seawater salinity Cfeed,ppm & 35000 & 36000 & 37000 & 38000 & 39000 & 40000 & 41000 & 42000 \\
\hline \multicolumn{9}{|c|}{ Production flow rates for MSF and RO processes } \\
\hline$W_{\mathrm{msf}}^{\mathrm{P}}, \mathrm{m}^{3} / \mathrm{h}$ & - & - & - & - & 132.4 & 210.6 & 285.9 & 358.5 \\
\hline$\left(W_{\text {rol }}{ }^{\mathrm{P}}+W_{\text {ro2 }}{ }^{\mathrm{P}}\right), \mathrm{m}^{3} / \mathrm{h}$ & 2000 & 2000 & 2000 & 2000 & 1867.6 & 1789.4 & 1714.1 & 1641.5 \\
\hline \multicolumn{9}{|l|}{ Seawater feed: Wfeed, $\mathrm{m}^{3} / \mathrm{h}$} \\
\hline MSF & - & - & - & - & 304.0 & 543.9 & 794.6 & 1057.7 \\
\hline RO1 & 4241.3 & 4373.0 & 4498.0 & 4790.1 & 4441.0 & 4376.8 & 4315.4 & 4256.7 \\
\hline $\mathrm{RO} 2$ & - & - & - & - & - & - & - & - \\
\hline \multicolumn{9}{|c|}{ Flow rates of the interconnection streams: $W, \mathrm{~m}^{3} / \mathrm{h}$} \\
\hline \begin{tabular}{|l} 
MSF \\
\end{tabular} & - & - & - & - & 1146.4 & 1808.6 & 2444.1 & 3044.2 \\
\hline MSF & - & - & - & - & 132.4 & 210.6 & 285.9 & 358.5 \\
\hline MSF & - & - & - & - & 725.4 & 1169.2 & 1599.3 & 1986.5 \\
\hline Rrol & - & - & - & - & - & - & - & - \\
\hline Rro2 & - & - & - & - & - & - & - & - \\
\hline Rbdw & - & - & - & - & 288.6 & 428.7 & 558.8 & 699.2 \\
\hline RO1 & 4241.3 & 4373.0 & 4498.0 & 4790.1 & 4441.0 & 4376.8 & 4315.4 & 4256.7 \\
\hline RO1 & 1499.6 & 1495.1 & 1492.3 & 1540.7 & 1385.2 & 1322.5 & 1262.4 & 1204.8 \\
\hline RO1 & - & - & - & - & - & - & - & - \\
\hline Rrol & - & - & - & - & - & - & - & - \\
\hline Rro2 & 2741.7 & 2877.9 & 3005.7 & 2808.8 & 3055.8 & 3054.3 & 3053.0 & 3051.8 \\
\hline Rbdw & - & - & - & 440.6 & - & - & - & - \\
\hline RO2 & 2741.7 & 2877.9 & 3005.7 & 2808.8 & 3055.8 & 3054.3 & 3053.0 & 3051.8 \\
\hline RO2 & 500.4 & 504.9 & 507.7 & 459.3 & 482.4 & 466.9 & 451.7 & 436.8 \\
\hline RO2 & - & - & - & - & 117.1 & 95.4 & 50.2 & - \\
\hline Rro1 & - & - & - & - & - & - & - & - \\
\hline Rro2 & - & - & - & - & - & - & - & - \\
\hline Rbdw & 2241.3 & 2373.0 & 2498.0 & 2349.5 & 2456.3 & 2492.0 & 2551.2 & 2615.0 \\
\hline \multicolumn{9}{|c|}{ Salt concentration of the interconnection streams: $C, \mathrm{ppm}$} \\
\hline MSF $\quad$ F & - & - & - & - & 60317.6 & 58059.1 & 56833.3 & 56050.2 \\
\hline MSF & - & - & - & - & 68194.8 & 65712.0 & 64363.0 & 63531.0 \\
\hline RO1 & 35000 & 36000 & 37000 & 38000 & 39000 & 40000 & 41000 & 42000 \\
\hline RO1 & 383.8 & 402.4 & 419.8 & 437.8 & 455.4 & 475.3 & 496.2 & 518.2 \\
\hline RO1 & 53934.2 & 54493.6 & 55160.9 & 55810.8 & 56472.6 & 57113.9 & 57747.9 & 58375.5 \\
\hline $\mathrm{RO} 2$ & 53934.2 & 54493.6 & 55160.9 & 55810.8 & 56472.6 & 57113.9 & 57747.9 & 58375.5 \\
\hline $\mathrm{RO} 2$ & 940.5 & 951.6 & 978.9 & 1013.6 & 1055.3 & 1095.3 & 1137.1 & 1180.6 \\
\hline $\mathrm{RO} 2 \quad \mathrm{R}$ & 65764.6 & 65884.8 & 66174.0 & 66522.5 & 66861.1 & 67221.6 & 67577.7 & 67928.1 \\
\hline Cost of fresh water, $\$ / \mathrm{m}^{3}$ & 0.6784 & 0.6952 & 0.7121 & 0.7410 & 0.7717 & 0.7985 & 0.8240 & 0.8486 \\
\hline
\end{tabular}




\begin{tabular}{|c|c|c|c|c|c|c|c|c|c|c|c|}
\hline \multicolumn{12}{|c|}{ Optimal solutions for the hybrid plant: MSF-RO. Design variables and operating conditions. } \\
\hline $\begin{array}{l}\text { Seawater } \\
\text { salinity: } \\
\text { Cfeed, ppm }\end{array}$ & 35000 & 36000 & 37000 & 38000 & 39000 & 40000 & 41000 & 42000 & 43000 & 44000 & 45000 \\
\hline \multicolumn{12}{|l|}{ MSF } \\
\hline $\begin{array}{l}\text { Qes, } \\
\text { Gcal/h }\end{array}$ & - & - & - & - & 8.80 & 12.93 & 16.78 & 20.46 & 23.89 & 27.10 & 30.14 \\
\hline NS & - & - & - & - & 19 & 23 & 26 & 28 & 30 & 32 & 33 \\
\hline$A_{S}, \mathrm{~m}^{2}$ & - & - & - & - & 828.8 & 1103.5 & 1332.8 & 1515.5 & 1679.8 & 1836.0 & 1957.8 \\
\hline$A_{t}, \mathrm{~m}^{2}$ & - & - & - & - & 11858.9 & 19552.9 & 27100.3 & 34308.4 & 40568.8 & 46406.2 & 52594.8 \\
\hline$\Delta t, \mathrm{~K}$ & - & - & - & - & 7.24 & 6.75 & 6.48 & 6.34 & 6.30 & 6.28 & 6.25 \\
\hline$\Delta t_{f}, \mathrm{~K}$ & - & - & - & - & 3.54 & 2.95 & 2.63 & 2.46 & 2.34 & 2.23 & 2.19 \\
\hline$\Delta t_{e}, \mathrm{~K}$ & - & - & - & - & 1.80 & 1.89 & 1.95 & 1.99 & 2.07 & 2.15 & 2.16 \\
\hline$N_{t}$ & - & - & - & - & 368 & 501 & 615 & 723 & 798 & 855 & 940 \\
\hline$L_{d}, \mathrm{~m}$ & - & - & - & - & 8.55 & 12.09 & 15.13 & 17.66 & 19.88 & 21.96 & 23.74 \\
\hline$H s, \mathrm{~m}$ & - & - & - & - & 1.45 & 1.53 & 1.58 & 1.63 & 1.66 & 1.67 & 1.72 \\
\hline$D_{S}, \mathrm{~m}$ & - & - & - & - & 0.45 & 0.53 & 0.58 & 0.63 & 0.66 & 0.67 & 0.72 \\
\hline$T_{\mathrm{msf}^{\mathrm{F}}}, \mathrm{K}$ & - & - & - & - & 310.5 & 310.3 & 310.3 & 309.9 & 308.6 & 307.4 & 306.3 \\
\hline$T_{\mathrm{msf}^{\mathrm{R}}}, \mathrm{K}$ & - & - & - & - & 317.7 & 317.1 & 316.7 & 316.2 & 314.9 & 313.7 & 312.6 \\
\hline \multicolumn{12}{|l|}{ RO1 } \\
\hline$N M_{1}$ & 4633 & 4777 & 4915 & 5232 & 4843 & 4773 & 4706 & 4642 & 4580 & 4520 & 4462 \\
\hline$P \mathrm{f}_{1}$, atm & 67.900 & 67.900 & 67.900 & 67.899 & 67.900 & 67.900 & 67.899 & 67.900 & 67.893 & 67.898 & 67.900 \\
\hline HPP1 & yes & yes & yes & yes & yes & yes & yes & yes & yes & yes & yes \\
\hline$T_{\text {ro1 }}, \mathrm{K}$ & 298.0 & 298.0 & 298.0 & 298.0 & 298.0 & 298.0 & 298.0 & 298.0 & 298.0 & 298.0 & 298.0 \\
\hline \multicolumn{12}{|l|}{ RO2 } \\
\hline$N M_{2}$ & 3129 & 3189 & 3286 & 3063 & 3332 & 3331 & 3330 & 3328 & 3327 & 3325 & 3323 \\
\hline$P^{f_{2}}$, atm & 67.868 & 67.868 & 67.868 & 67.866 & 67.867 & 67.867 & 67.867 & 67.867 & 67.860 & 67.865 & 67.866 \\
\hline HPP2 & no & no & no & no & no & no & no & no & no & no & no \\
\hline$T_{\text {ro2 }}, \mathrm{K}$ & 298.0 & 298.0 & 298.0 & 298.0 & 298.0 & 298.0 & 298.0 & 298.0 & 298.0 & 298.0 & 298.0 \\
\hline
\end{tabular}

Table 4. Optimal solutions for the hybrid plant: design variables and operating conditions

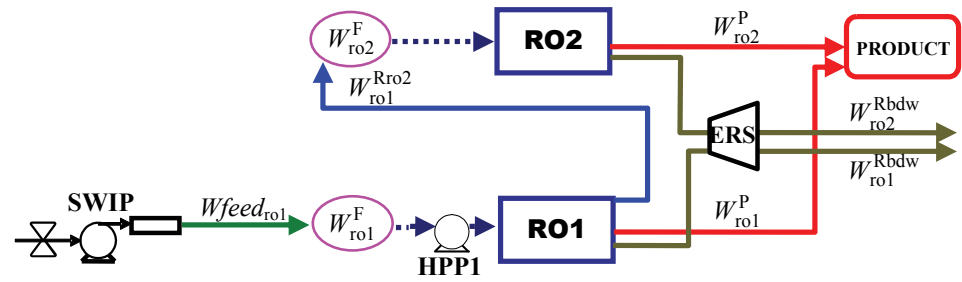

Fig. 5. Scheme of the optimal design for seawater salinities between 35000 and 38000 ppm

The stream with flow rate $W_{\text {ro1 }}{ }^{\mathrm{Rbdw}}$ is only present for $38000 \mathrm{ppm}$ of seawater salinity. For salinities lower than $38000 \mathrm{ppm}$, the totality of the stream rejected from the first RO stage: system RO1, enters into the second $\mathrm{RO}$ stage: system RO2. Then, the stream entering into the system $\mathrm{RO} 2$ is sufficiently pressurized. Therefore, the high pressure pumps before system RO2 are avoided in the optimal solutions. This decision is properly made by the optimization procedure, and it is correctly reflected in the cost function. 
Figure 6 shows a scheme of the optimal solutions obtained for seawater salt concentrations between 39000 and 45000 ppm.

For these case studies, both desalination processes are present at the optimal hybrid plant design. The RO systems work as a two-stage RO plant, i.e.: system RO1 is fed directly from sea, while its rejected stream is the fed stream for system RO2. No other streams are blended to feed RO systems.

Regarding MSF system, it operates with an important recycle. This re-circulated stream reduces the chemical pre-treatment and raises the feed stream temperature with the consequent reduction of external heat consumption. Both factors straightly impact on the final cost.

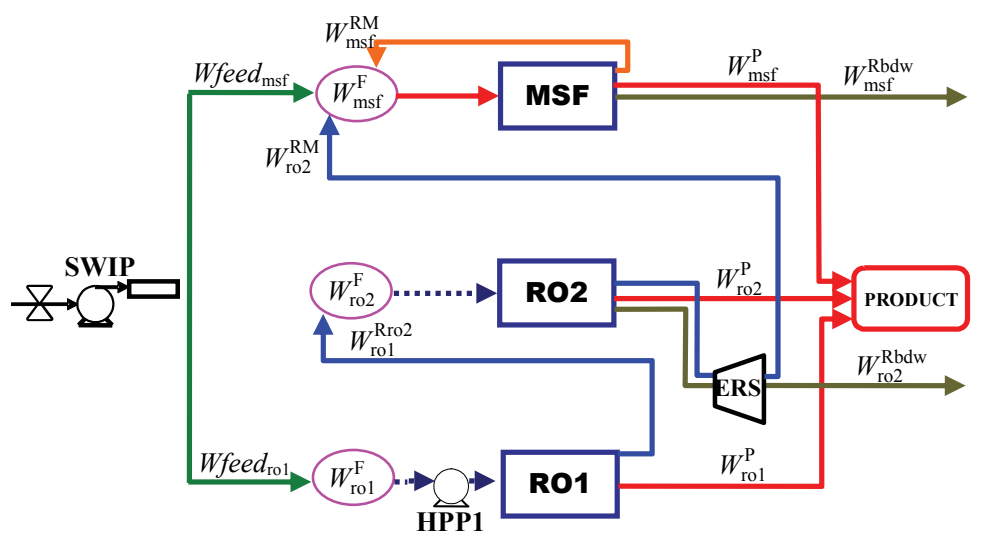

Fig. 6. Scheme of the optimal design for seawater salinities between 39000 and 45000 ppm

As it is also shown in Table 3, the three first cases presented in Figure 6 include the stream with flow rate $W_{\text {ro } 2}{ }^{R M}$. However, for seawater salt concentrations higher than $41000 \mathrm{ppm}$ this flow rate is null and the stream does not exist. Then, for the last four case studies, even though the two desalination processes are selected for the optimal plant design, they operate in independent way. In fact: there is no stream connecting the MSF and RO processes. However, both processes share the intake and pre-treatment system. Furthermore, the salinity of the product stream satisfies the maximum allowed salt concentration requirement because the three product streams are blended. As it can be seen at Table 3, if only the permeate streams coming from $\mathrm{RO}$ systems are blended, then the salt concentration of the resulting stream will be far above the maximum allowed salt concentration.

Again, the stream feeding system $\mathrm{RO} 2$ is composed only by the stream rejected from system RO1 and it is high pressurized. Thus, the high pressure pumps before system RO2 are unnecessary and consequently, they are avoided at the optimal design.

Figure 7 shows the fresh water produced by each desalination process for all the case studies.

As it was mentioned, for seawater salt concentrations below $38000 \mathrm{ppm}$, MSF system is not present, thus the demand is totally satisfied by RO systems. On the other hand, for seawater salinities higher than $38000 \mathrm{ppm}$, both processes contribute to satisfy the demand. Although the RO systems produce more fresh water than MSF system, the MSF production increases according to the seawater salinity rise. 


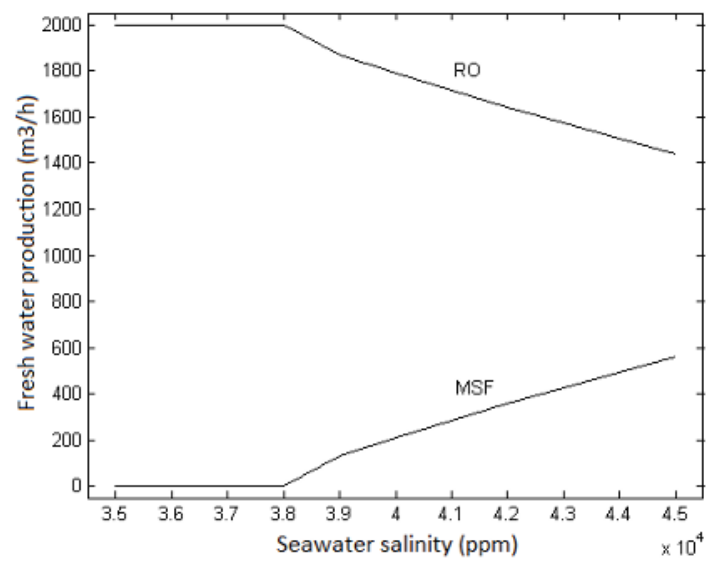

Fig. 7. Fresh water production

If the MSF system would not be considered, for the optimal design of a two stage RO plant the capacity of the second stage will decrease when the seawater salinity increases (Marcovecchio et al., 2005). In fact, even though the stream rejected from the first RO stage is high pressurized and it could enter into a second stage with no need of high pressure pumps; in the optimal design, part of this stream is discharged back to the sea. The second stage capacity will continue decreasing until only one RO stage is the optimal design for high feed salt concentration. The reason why it is no longer profitable to use the stream rejected from the first $\mathrm{RO}$ stage is that its salinity is too high. Thus, the salt concentration of the potential permeate will be lower but also high and then, it is not possible to satisfy the maximum allowed salt concentration even by blending with the first stage permeate. Therefore, the fresh water produced by the first stage must be higher in order to satisfy the demand. Consequently, the flow rate of seawater is increased. As a consequence, the cost per $\mathrm{m}^{3}$ of fresh water increases, since many costs are directly affected.

Contrary, in a hybrid plant where the MSF process is available, in that break point where the optimal design of a $\mathrm{RO}$ plant changes, it begins to be profitable to complement the $\mathrm{RO}$ production with distillated from MSF system.

Then, for feed salinities higher than 38000 ppm, the growth of MSF system production is approximately linear. With this plant design, there is no stream rejected from the first RO stage being discharged back to the sea, i.e. the totality of that stream enters into the second RO stage. And the total production of the plant reaches the requirement of maximum allowed salt concentration by blending the slightly concentrated permeate from RO systems with the free of salt distillate of MSF process.

Finally, Figure 8 compares the cost per $\mathrm{m}^{3}$ of fresh water produced with the optimal configurations obtained for the hybrid plant with those obtained for the RO stand alone plant.

As it is shown in Figure 8, the cost reduction reached with the hybrid RO-MSF plant is considerable. For feed salinities between 39000 and 44000 ppm, the cost function has an 


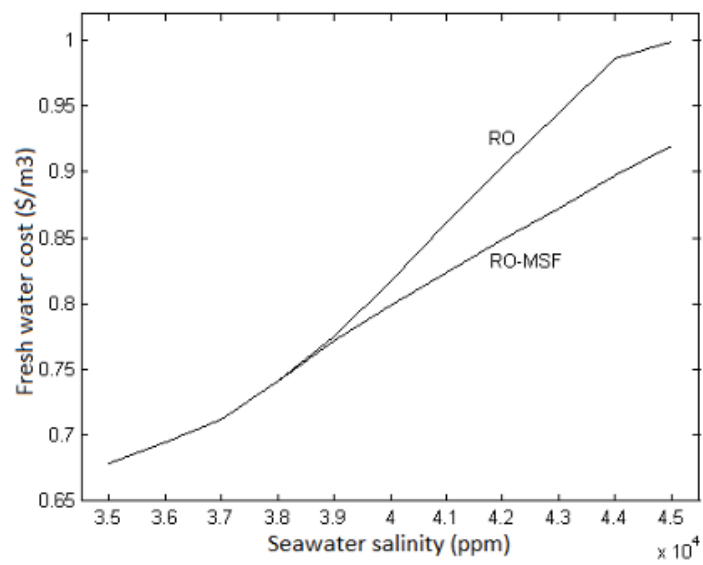

Fig. 8. Fresh water cost for hybrid RO-MSF plants and RO stand alone plants

almost linear growth with respect to the seawater salinity, for both: $\mathrm{RO}$ and hybrid plant. However, the growth rate associated to the hybrid plant cost is far lower.

For comparative purposes, optimal designs for the MSF stand alone plant were calculated. That is, it was calculated the cost per $\mathrm{m}^{3}$ of fresh water produced by the MSF-once through process satisfying the same demand: $2000 \mathrm{~m}^{3} / \mathrm{h}$. In the implemented model, this cost is not affected by the feed salinity. The cost obtained for the case studies was $\$ 1.1683$. Also, the designs obtained are the same for all the case studies, since the only constraint that could affect the solution is the one requiring that the concentration of the stream discharged back to sea be lower than $67000 \mathrm{ppm}$, but this limit is not reached in any case.

\section{Conclusion}

In this work, a MINLP mathematical model for the optimal synthesis and design of hybrid desalination plants, including the two conversion processes: reverse osmosis and multiple stage flash evaporation, was presented.

The MSF model is based on a previous work presented by (Mussati et al., 2004). It involves real-physical constraints for the evaporation process and is derived on energy, mass and momentum balances. In addition, geometric dimensions of stages including chambers and pre-heaters are considered as optimization variables. Heat exchange areas of condensers are also design variables to be determined.

The RO model with hollow fiber permeators is based on the work (Marcovecchio et al., 2005). For this model, the transport phenomena of solute and water through the membrane are modelled by Kimura-Sourirajan model. The concentration polarization phenomenon is taken into account. The Hagen-Poiseuille and Ergun equations are employed to calculate the pressure drops. In the RO model, the number of permeators operating in parallel, the operating pressure and flow rates are the main optimization variables.

The modelled hybrid plant includes two RO and one MSF systems. The proposed superstructure allows optimizing not only operating conditions but also process configurations simultaneously. Thus, the model includes network constraints which are related to all potential interconnections between the three systems. 
Network constraints ensure the correct definition of flow rates, salt concentrations and temperatures for each stream.

Cost equations take into account all the factors affecting the cost of each process. Certainly, capital investment and operating cost of all process equipments were considered.

Optimal solutions for eleven case studies were obtained, for different seawater salinities. Then optimal designs and operating conditions were determined by minimizing the cost per $\mathrm{m}^{3}$ of produced fresh water. Cost equations are able to reflect accurately the presence or absence of certain equipment, stream or even a whole system.

From the optimal solutions, it can be concluded that the RO stand alone plant is the best option for feed salinities between 35000 and 38000 ppm. In fact, the optimal design obtained for these cases consist on a two-stage RO plant while the MSF process was completely eliminated.

However, when the seawater salinity rises, it is profitable to integrate the MSF system in a hybrid plant. Actually, for feed salinities higher than 38000 ppm both desalination processes are present at the optimal plant design. In these cases, the integration of MSF process allows a better use of the rejected streams leaving the first and second RO stages. As a consequence, the final fresh water cost is reduced. It is important to note that although the RO production is higher than the MSF one, the MSF capacity increases according to the seawater salinity rise.

Then, important conclusions about the relationship between membrane and thermal desalination processes can be established from the optimal solutions presented in this work. In fact, the optimal hybrid plants were described for different seawater conditions, in order to minimize the cost of producing fresh water.

In future works, more detailed models for each process will be included in the superstructure problem, in order to improve the model presented here. In addition, other interconnections between the two studied processes will be considered, as the incorporation of streams coming from RO system in different stages of the MSF evaporator. Then, the interaction between both desalination processes will be more flexible and may lead to reduce the total cost of the process.

\section{Acknowledgements}

The authors acknowledge financial support from 'Agencia Nacional de Promoción Científica y Tecnológica' (ANCyT), and 'Consejo de Investigaciones Científicas y Técnicas' (CONICET), Argentina.

\section{Nomenclature}

\section{Subscripts}

msf Multi Stage Flash System

ro1 Reverse Osmosis System 1

ro2 Reverse Osmosis System 2

\section{Superscripts}

F $\quad$ Feed

P Permeate - Product 
$\mathrm{R} \quad$ Rejected - Concentrated brine

Rbdw Rejected to be blown down

RM Rejected brine entering into MSF system

Rro1 Rejected brine entering into RO1 system

Rro2 Rejected brine entering into RO1 system

$\rho^{\mathrm{b}} \quad$ brine density - $\mathrm{RO}, \mathrm{kg} / \mathrm{m}^{3}$

$\rho^{\mathrm{p}} \quad$ pure water density - $\mathrm{RO}, \mathrm{kg} / \mathrm{m}^{3}$

$\mu^{\mathrm{b}} \quad$ brine viscosity - $\mathrm{RO}, \mathrm{kg} /(\mathrm{m} \mathrm{s})$

$\mu \mathrm{P} \quad$ permeated stream viscosity $-\mathrm{RO}, \mathrm{kg} /(\mathrm{m} \mathrm{s})$

$\lambda \quad$ latent heat evaporation - MSF, Kcal / $\mathrm{kg}$

$Q^{\mathrm{f}} \quad$ feed flow rate per membrane module - RO, $\mathrm{m}^{3} / \mathrm{h}$

$Q^{p} \quad$ permeate flow rate per membrane module - $\mathrm{RO}, \mathrm{m}^{3} / \mathrm{h}$

$Q^{b} \quad$ brine flow rate inside the shell per membrane module - $\mathrm{RO}, \mathrm{m}^{3} / \mathrm{h}$

$\mathrm{Cm} \quad$ salt concentration at the membrane wall - $\mathrm{RO}$, ppm

$\rho_{\text {vap }} \quad$ vapor density - MSF, $\mathrm{kg} / \mathrm{m}^{3}$

$\Delta t \quad$ temperature drop - MSF, K

Jw water flux $-\mathrm{RO}, \mathrm{kg} / \mathrm{m}^{2} . \mathrm{h}$

Js solute flux $-\mathrm{RO}, \mathrm{kg} / \mathrm{m}^{2} \cdot \mathrm{h}$

$\varepsilon \quad$ void fraction - $\mathrm{RO}$

$\Delta t_{e} \quad$ effective driving force for the heat transfer operation - MSF, K

$\Delta t_{f} \quad$ temperature drop for the flashing operation - MSF, K

$P_{\mathrm{f}} \quad$ feed stream pressure - $\mathrm{RO}$, atm

$\bar{P}^{\mathrm{p}} \quad$ Average pressure in the fiber bore $-\mathrm{RO}$, atm

$\bar{P}^{\mathrm{b}} \quad$ Average pressure on the shell side of the fiber bundle $-\mathrm{RO}$, atm

$V \mathrm{w} \quad$ velocity of permeation flow $-\mathrm{RO}, \mathrm{m} / \mathrm{h}$

$U^{\text {so }} \quad$ Superficial velocity at the outer radius of the fiber bundle $-\mathrm{RO}, \mathrm{m} / \mathrm{s}$

$U^{\mathrm{si}} \quad$ Superficial velocity at the inner radius of the fiber bundle $-\mathrm{RO}, \mathrm{m} / \mathrm{s}$

$U^{\mathrm{S}} \quad$ superficial velocity in the radial direction of the bulk stream - $\mathrm{RO}, \mathrm{m} / \mathrm{s}$

A pure water permeability constant - $\mathrm{RO}, \mathrm{kg} / \mathrm{m}^{2} . \mathrm{s}$.atm

$A_{\mathrm{m}} \quad$ module membrane area - $\mathrm{RO}, \mathrm{m}^{2}$

AOC Annual operating cost, \$/y

As Total stage surface area - MSF, $\mathrm{m}^{2}$

$A_{t} \quad$ total heat transfer area - MSF, $\mathrm{m}^{2}$

$B \quad$ solute permeability constant $-\mathrm{RO}, \mathrm{m} / \mathrm{s}$

$B_{\mathrm{msf}} \quad$ chamber width - MSF, $\mathrm{m}$

$B P E \quad$ boiling point elevation, $\mathrm{K}$

C salt concentration, ppm

$c c_{\text {area }} \quad$ capital cost of heat transfer area of MSF system, \$

$c \mathcal{C}_{\mathrm{cw}} \quad$ capital cost of civil work, $\$$

$c c_{\text {eq }}$ total equipment cost, \$

$\mathcal{C C}_{\text {ers }} \quad$ capital cost for the Energy Recovery System, \$

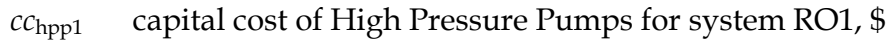

${ }^{c} C_{\text {hpp2 }}$ capital cost of High Pressure Pumps for system RO2, \$ 
$c C_{\mathrm{i}} \quad$ indirect capital cost, $\$$

$c_{\text {swip }} \quad$ capital cost for the Seawater Intake and Pre-treatment system, \$

Cfeed feed salt concentration, ppm

$c_{\max }$ maximum salt concentration allowed for the product stream, ppm

$\mathrm{CO}_{\mathrm{c}} \quad$ capital charge cost, \$/year

$\mathrm{Co}_{\mathrm{ch}} \quad$ chemical treatment cost, \$/year

$\mathrm{CO}_{\mathrm{e}} \quad$ energy cost, \$/year

$\mathrm{CO}_{\mathrm{ht}} \quad$ cost of the heat consumed by system MSF, \$/year

$\mathrm{Co}_{\mathrm{om}}$ general operation and maintenance cost, \$/year

$\mathrm{Co}_{\mathrm{pw}}$ power cost for system MSF, \$/year

$\mathrm{Co}_{\mathrm{rp}} \quad$ cost of permeator replacement, $\$ /$ year

$\mathrm{Co}_{\mathrm{s}} \quad$ spares cost, \$/year

cost cost per $\mathrm{m}^{3}$ of produced fresh water, $\$ / \mathrm{m}^{3}$

$C p_{\text {msf }}$ heat capacity - MSF, Kcal / ( $\left.\mathrm{kg} \mathrm{K}\right)$

crf capital recovery factor

$D$ diffusivity coefficient - $\mathrm{RO}, \mathrm{m}^{2} / \mathrm{s}$

$d_{\mathrm{p}} \quad$ specific surface diameter - $\mathrm{RO}, \mathrm{m}$

Ds shell diameter - MSF, $\mathrm{m}$

effers energy recovery system efficiency

eff hpp high pressure pumps efficiency

eff $f_{\text {swip }}$ intake pump efficiency

$f_{\mathrm{c}} \quad$ load factor

Hs chamber height - MSF, m

$i$ number of ions for ionized solutes - $\mathrm{RO}$

$k$ mass transfer coefficient - $\mathrm{RO}, \mathrm{m} / \mathrm{s}$

$L \quad$ length of fiber bundle - $\mathrm{RO}, \mathrm{m}$

$\mathrm{Lb} \quad$ level of brine in the flashing chamber - MSF, $\mathrm{m}$

$L_{d} \quad$ length of desaltor - MSF, $\mathrm{m}$

Ms solute molecular weight - $\mathrm{RO}$

NM number of membrane module operating in parallel mode in each RO system

$N_{r t} \quad$ number of rows in the vertical direction - MSF

NS number of flashing stages - MSF

$N_{t} \quad$ number of tubes - MSF

$P$ in $\quad$ pressure of the stream entering into each $\mathrm{RO}$ system - $\mathrm{RO}$, atm

prodc total plant production, $\mathrm{m}^{3} / \mathrm{h}$

$P_{\text {swip }} \quad$ seawater intake system outlet pressure, bar

$P_{t} \quad$ Pitch - MSF

$Q^{\text {Des }} \quad$ external heat consumption - MSF, Gcal/h

$R \quad$ ideal gas constant - $\mathrm{RO}, \mathrm{N} \mathrm{m} /(\mathrm{kgmol} \mathrm{K})$

Re Reynolds number $\left(2 \cdot r_{0} \cdot U_{\mathrm{s}}^{\mathrm{s}} \cdot \rho^{\mathrm{b}} / \mu^{\mathrm{b}}\right)-\mathrm{RO}$

$R_{\mathrm{i}} \quad$ inner radius of the fiber bundle - RO, $\mathrm{m}$

$r_{\mathrm{i}} \quad$ inner fiber radius - $\mathrm{RO}, \mathrm{m}$

$R_{\mathrm{o}} \quad$ outer radius of the fiber bundle - RO, $\mathrm{m}$

$r_{\mathrm{o}} \quad$ outer fiber radius - $\mathrm{RO}, \mathrm{m}$ 
Sc $\quad$ Schmidt number $\left(\mu^{\mathrm{b}} / \rho^{\mathrm{b}} . D\right)-\mathrm{RO}$

Sh Sherwood number $\left(2 . k . r_{\mathrm{o}} / D\right)-\mathrm{RO}$

$T$ temperature, $\mathrm{K}$

TCC total capital cost, $\$$

TD tube diameter - MSF, $\mathrm{m}$

Tfeed seawater temperature, $\mathrm{K}$

$T_{\max } \quad$ maximum brine temperature - MSF, $\mathrm{K}$

$U \quad$ overall heat transfer coefficient - MSF, Kcal / $\left(\mathrm{K} \mathrm{m}^{2} \mathrm{~h}\right)$

$V_{\text {vap }} \quad$ vapor velocity - MSF, $\mathrm{m} / \mathrm{s}$

$W \quad$ flow rate, $\mathrm{m}^{3} / \mathrm{h}$

Wfeed seawater feed flow, $\mathrm{m}^{3} / \mathrm{h}$

\section{References}

Agashichev, S.P. (2004). Analysis of integrated co-generative schemes including MSF, RO and power generating systems (present value of expenses and "levelised" cost of water). Desalination, 164 (3): 281-302, ISSN: 0011-9164.

Al-Bastaki, N.M. \& Abbas, A. (1999). Modeling an industrial reverse osmosis unit. Desalination 126 (1-3): 33-39, ISSN: 0011-9164.

Brooke, A.; Kendrick, D.; Meeraus, A. \& Raman, R. (1997). GAMS Language Guide, Release 2.25, Version 92. GAMS Development Corporation.

Cardona, E. \& Piacentino, A. (2004). Optimal design of cogeneration plants for seawater desalination. Desalination 166: 411-426, ISSN: 0011-9164.

Helal, A.M.; El-Nashar, A.M.; Al-Katheeri, E. \& Al-Malek, S. (2003). Optimal design of hybrid RO/MSF desalination plants. Part I: Modeling and algorithms. Desalination 154 (1): 43-66, ISSN: 0011-9164.

Kimura, S. \& Sourirajan, S. (1967). Analysis of data in reverse osmosis with porous cellulose acetate membranes. AIChE Journal 13 (3): 497-503, ISSN: 1547-5905.

Malek, A.; Hawlader, M.N.A. \& Ho, J.C. (1996). Design and economics of RO seawater desalination. Desalination 105 (3): 245-261, ISSN: 0011-9164.

Marcovecchio, M.G.; Aguirre, P.A. \& Scenna, N.J. (2005). Global optimal design of reverse osmosis networks for seawater desalination: modeling and algorithm. Desalination 184 (1-3): 259-271, ISSN: 0011-9164.

Marcovecchio, M.G.; Mussati, S.F.; Aguirre, P.A. \& Scenna, N.J. (2005). Optimization of hybrid desalination processes including multi stage flash and reverse osmosis systems. Desalination 182 (1-3): 111-122, ISSN: 0011-9164.

Marcovecchio, M.G.; Mussati, S.F.; Scenna, N.J. \& Aguirre, P.A. (2009). Global optimal synthesis of integrated hybrid desalination plants, Computer Aided Chemical Engineering, Vol 26: 573-578, ISBN-13: 978-0-444-53433-0. Elsevier Science B.V. 19th European Symposium on Computer Aided Process Engineering (ESCAPE19), 14-17 June 2009. Cracow, Poland.

Mussati, S.F.; Aguirre, P.A. \& Scenna, N.J. (2006). Superstructure of alternative Configurations of the multistage flash desalination process. Industrial \& Engineering Chemistry Research 45 (21): 7190-7203, ISSN: 0888-5885. 
Mussati, S.F.; Marcovecchio, M.G.; Aguirre, P.A. \& Scenna, N.J. (2004). A new global optimization algorithm for process design: its application to thermal desalination processes. Desalination 166: 129-140, ISSN: 0011-9164.

Voros, N.G. ; Maroulis, Z.B. \& Marinos-Kouris, D. (1997). Short-cut structural design of reverse osmosis desalination plants. Journal of Membrane Science 127 (1): 47-68, ISSN: 0376-7388.

Wade, N.M. (2001). Distillation plant development and cost update. Desalination 136 (1-3): 312, ISSN: 0011-9164. 


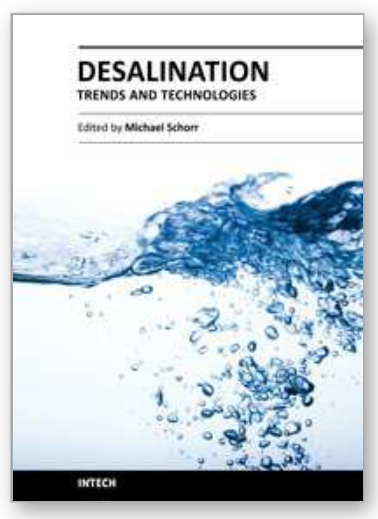

\author{
Desalination, Trends and Technologies \\ Edited by Michael Schorr
}

ISBN 978-953-307-311-8

Hard cover, 334 pages

Publisher InTech

Published online 28, February, 2011

Published in print edition February, 2011

The book comprises 14 chapters covering all the issues related to water desalination. These chapters emphasize the relationship between problems encountered with the use of feed water, the processes developed to address them, the operation of the required plants and solutions actually implemented. This compendium will assist designers, engineers and investigators to select the process and plant configuration that are most appropriate for the particular feed water to be used, for the geographic region considered, as well as for the characteristics required of the treated water produced. This survey offers a comprehensive, hierarchical and logical assessment of the entire desalination industry. It starts with the worldwide scarcity of water and energy, continues with the thermal - and membrane-based processes and, finally, presents the design and operation of large and small desalination plants. As such, it covers all the scientific, technological and economical aspects of this critical industry, not disregarding its environmental and social points of view. One of InTech's books has received widespread praise across a number of key publications. Desalination, Trends and Technologies (Ed. Schorr, M. 2011) has been reviewed in Corrosion Engineering, Science \& Technology - the official magazine for the Institute of Materials, Minerals \& Mining, and Taylor \& Francis's Desalination Publications. Praised for its "multi-faceted content [which] contributes to enrich it," and described as "an essential companion... [that] enables the reader to gain a deeper understanding of the desalination industry," this book is testament to the quality improvements we have been striving towards over the last twelve months.

\title{
How to reference
}

In order to correctly reference this scholarly work, feel free to copy and paste the following:

Marian G. Marcovecchio, Sergio F. Mussati, Nicolás J. Scenna and Pio A. Aguirre (2011). Optimization of Hybrid Desalination Processes Including Multi Stage Flash and Reverse Osmosis Systems, Desalination, Trends and Technologies, Michael Schorr (Ed.), ISBN: 978-953-307-311-8, InTech, Available from: http://www.intechopen.com/books/desalination-trends-and-technologies/optimization-of-hybrid-desalinationprocesses-including-multi-stage-flash-and-reverse-osmosis-system

\section{INTECH}

open science | open minds

\author{
InTech Europe \\ University Campus STeP Ri \\ Slavka Krautzeka 83/A
}

\author{
InTech China \\ Unit 405, Office Block, Hotel Equatorial Shanghai \\ No.65, Yan An Road (West), Shanghai, 200040, China
}


51000 Rijeka, Croatia

Phone: +385 (51) 770447

Fax: +385 (51) 686166

www.intechopen.com
中国上海市延安西路65号上海国际贵都大饭店办公楼 405 单元 Phone: +86-21-62489820

Fax: +86-21-62489821 
(C) 2011 The Author(s). Licensee IntechOpen. This chapter is distributed under the terms of the Creative Commons Attribution-NonCommercialShareAlike-3.0 License, which permits use, distribution and reproduction for non-commercial purposes, provided the original is properly cited and derivative works building on this content are distributed under the same license. 